\title{
Effect of Epigallocatechin Gallate on Viability of Kudoa septempunctata
}

\author{
Sang Phil Shin ${ }^{1}$, Hyun Ki Hong², Chang Nam Jin', Hanchang Sohn¹, Kwang Sik Choi², Jehee Lee ${ }^{1, *}$ (b) \\ ${ }^{1}$ Department of Marine Life Sciences \& Marine Science Institute, Jeju National University, Jeju Self-Governing Province 63243, Korea; \\ ${ }^{2}$ Department of Marine Life Science (BK FOUR) and Marine Science Institute, Jeju National University, Jeju Self-Governing Province 63243, Korea
}

\begin{abstract}
Kudoa septempunctata have been reported as a causative agent for acute transient gastrointestinal troubles after eating raw olive flounder (Paralichthys olivaceus). It raised public health concerns and quarantine control in several countries. Quantitative evaluation on viability of $K$. septempunctata is crucial to develop effective chemotherapeutics against it. A cytometry using fluorescent stains was employed to assess effect of three compounds on viability of $K$. septempunctata. Epigallocatechin gallate reduced markedly viability of $K$. septempunctata at $0.5 \mathrm{mM}$ or more, and damaged K. septempunctata spores by producing cracks.
\end{abstract}

Key words: Kudoa septempunctata, olive flounder, flow cytometry, epigallocatechin gallate

Myxozoa (Cnidaria) include more than 2,100 species, most of which are coelozoic or histozoic parasites in fish [1]. Although most myxozoans do not cause a serious problem in fish, several species Enteromyxum leei, E. scophthalmi, and Myxobolus cerebralis cause mass mortality [2-4], and Kudoa septempunctata, K. iwatai, K. hexapunctata, and Unicapsula seriolae have been reported to cause fish-born illness in Korea and Japan [5-8]. In particular, K. septempunctata has been reported in olive flounder Paralichthys olivaceus, which is the most reared fish species in Korea. This species provoked a conflict in fish trade and economic loss in fish farming [9].

Based on the differences in fluorescent stains and morphological changes of the myxozoa, several studies have been conducted to find chemotherapeutic agents that affect the viability of K. septempunctata [10-12]. However, the quantification and determination of accurate effective doses of chemicals based on microscopic observation can lead to inconsistency and misinterpretations, particularly due to subjective visual criteria. As an alternative, flow cytometry allows rapid, accurate, and quantitative analysis on cell morphology and viability. Flow cytometry has been applied to determine viability of the protozoans such as Crytosporidium parvum and Perkinsus marinus

\footnotetext{
- Received 5 May 2020, revised 8 September 2020, accepted 12 September 2020.

*Corresponding author (jehee@jejunu.ac.kr)

(C) 2020, Korean Society for Parasitology and Tropical Medicine

This is an Open Access article distributed under the terms of the Creative Commons Attribution Non-Commercial License (https://creativecommons.org/licenses/by-nc/4.0) which permits unrestricted non-commercial use, distribution, and reproduction in any medium, provided the original work is properly cited.
}

$[13,14]$. However, any assay on the viability of the myxozoans was performed using flow cytometry. Aim of present study is to assay on effect of three chemicals compounds to the viability of $K$. septempunctata spores using a simple and objective method of flow cytometry.

Olive flounders $(n=20)$ were obtained from an olive flounder farm that suffered annually from K. septempunctata infection. Squash preparations of the fish samples were examined microscopically to detect $K$. septempunctata spores. The spores were purified by a modified Percoll (Sigma-Aldrich, St. Louis, Missouri, USA) density-gradient centrifugation method, as previously described [15]. The K. septempunctata spores were exposed to three kinds of chemicals including amprolium hydrochloride (AH; Dr. Ehrenstorfer, Augsburg, Germany), chlorogenic acid (CA; Carl Roth, Karlsruhe, Germany), and epigallocatechin gallate (EGCG; Sigma-Aldrich), which have been reported to be effective against the myxospores [11,12]. Fifty microliters of chemicals ( 1 and $10 \mathrm{mM}$ ) were added to $450 \mu \mathrm{l}$ of phosphate-buffered saline (PBS) containing $3.2 \times 10^{5}$ spores, and the mixtures were incubated at room temperature (approximately $20-25^{\circ} \mathrm{C}$ ) for $30 \mathrm{~min}$. The spores were then stained with $50 \mu \mathrm{l}$ of $20 \mu \mathrm{g} / \mathrm{ml}$ propidium iodide (PI) for $10 \mathrm{~min}$. The proportion of dead and live spores was calculated to estimate viability based on 3,000 spores counted by the red fluorescence detector of the flow cytometer (CytoFlex, Beckman Coulter, Brea, California, USA).

To determine the criteria of viability of $K$. septempunctata, the spores $\left(8.5 \times 10^{3}\right.$ spores $\left./ 500 \mu \mathrm{l}\right)$ were exposed to PBS, $1 \%$ for- 
malin, and 0.01 and $0.1 \mathrm{mM}$ final concentrations of EGCG. It determined that the PBS exposed group 100\% viability while the $1 \%$ formalin exposed group has $0 \%$ viability. We investigated the effect of EGCG at concentrations, ranging from 0.01 to $1 \mathrm{mM}$. The flow cytometry assay was performed with $1.7 \times 10^{4}$ spores/500 $\mu \mathrm{l}$ exposed to $0.01,0.05,0.1$, and $1 \mathrm{mM}$ final concentrations of EGCG, and PBS. For scanning electron microscopy (SEM), the purified spores were divided into 3 groups that exposed to 0.1 and $1 \mathrm{mM} \mathrm{EGCG}$, and PBS for $30 \mathrm{~min}$, respectively. The spores were immediately rinsed twice with PBS and fixed in 2\% glutaraldehyde in $0.1 \mathrm{M}$ phosphate buffer ( $\mathrm{pH} 7.4$ ) at room temperature for $2 \mathrm{hr}$. The spores were post-fixed in 1\% osmium tetroxide in the same buffer and dehydrated through 50, 70, 90, 95, and 100\% ethanol each for $10 \mathrm{~min}$. The spores were dried in an atmosphere and then dried using a $\mathrm{CO}_{2}$ critical point dryer. Finally, the spores were sputter coated with platinum, and observed using a JSM-6700F SEM at $10 \mathrm{kV}$.

Since PI is permeable only through the membrane of dead K. septempunctata spores, intensity of the stain was counted as dead spores. The spores exposed to 0.1 and $1 \mathrm{mM}$ of CA and AM were unstained with PI since there was no damage in the membrane (Fig 1A). On the other hand, the spores treated with 0.1 and $1 \mathrm{mM}$ EGCG showed strong red fluorescence, indicating that the spores lost membrane integrity and were stained with PI (Fig. 1A). The efficacy of EGCG was found at $0.1 \mathrm{mM}$, but not at $0.01 \mathrm{mM}$. The finding/efficacy was similar to that of $1 \%$ formalin (Fig. 1B). We observed that more than $90 \%$ of the spores were dead in EGCG concentrations $\geq 0.5 \mathrm{mM}$. The effect of EGCG on the viability of $K$. septempunctata was depended on EGCG concentration (Fig. 2A-E). The evaluation of viability using flow cytometer was completed under $5 \mathrm{~min}$.

It was reported several chemicals affecting the viability of $K$. septempunctata using approximately 100 spores with two kinds of fluorescent stains to identify the dead/live spores [11,12]. In our study, the viability of 5,000 spores was determined using one fluorescent stain. Ahn et al. [11] reported that AH had an anti-Kudoa effect at higher concentrations $\geq 1 \mathrm{mM}$ and at longer treatment time ( $48 \mathrm{hr}$ ). The candidate chemicals should have anti-Kudoa effect at lower concentrations and in a shorter time since it will be used in fish farms. Ohnishi et al. [12] reported the anti-Kudoa effect of extract of coffee and tea, caffeine, and EGCG. The caffeine did not show any effect at $1 \mathrm{mM}$ concentration, whereas $100 \%$ of $K$. septempunctata spores were inactivated at $0.1 \mathrm{mM}$ EGCG. They proposed that the EGCG is an excellent candidate for the treatment and prevention of $K$. sep-
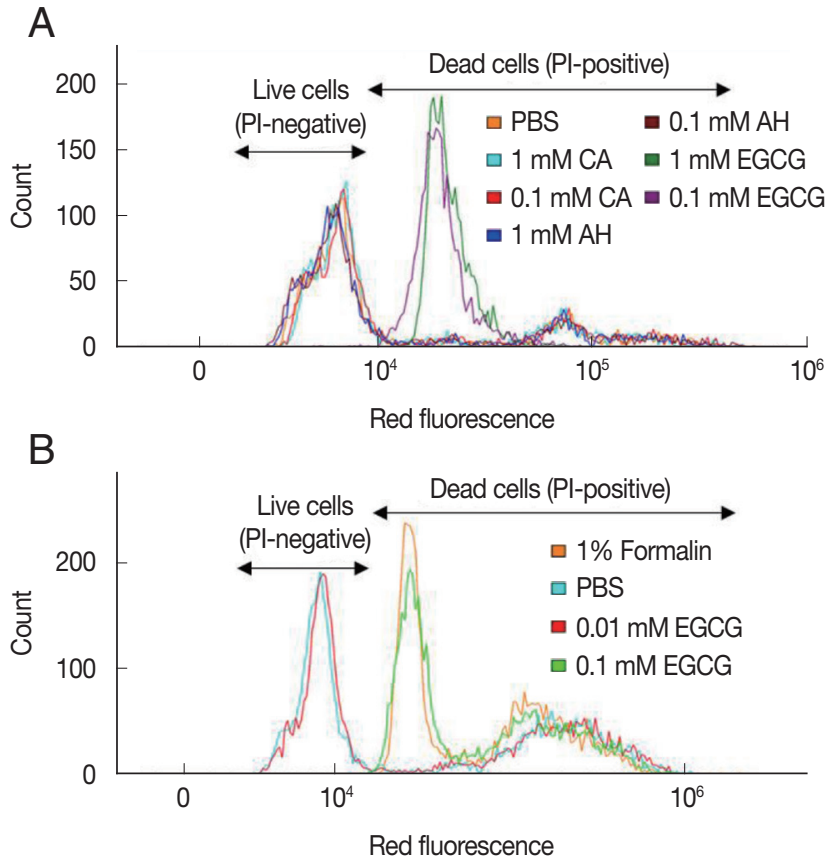

Fig. 1. Assessment of viability of Kudoa septempunctata myxospores using flow cytometry and propidium iodide staining. (A) The myxospores were treated with PBS, and 0.1 and $1 \mathrm{mM}$ of amprolium hydrochloride (AH), chlorogenic acid (CA), and epigallocatechin gallate (EGCG). (B) The myxospores were treated with PBS, $1 \%$ formalin, and 0.01 and $0.1 \mathrm{mM} \mathrm{EGCG.}$

tempunctata infection and emphasized the need to investigate other chemicals, such as chlorogenic acid (coffee ingredient). The present study also showed a complete anti-Kudoa effect of EGCG at $0.1 \mathrm{mM}$ or more. There was, however, a difference of anti-Kudoa effect (36.9\% vs. $80.6 \%$ dead spores) in the 0.01 mM EGCG groups different treatment time (30 min vs. $4 \mathrm{hr}$ ). In addition, we did not find any anti-Kudoa effect when spores were treated with CA. Consequently, we suggest that the EGCG has an anti-Kudoa effect at low concentrations and short treatment times as well as it is more efficient than CA in affecting the viability of $K$. septempunctata in vitro.

We speculated that EGCG effects on the integrity of shell valves of K. septempunctata spores, and it was confirmed by SEM. The spores in the PBS group showed intact surface feature (Fig. 3A and D). The spores treated with $0.1 \mathrm{mM}$ EGCG showed partial cracks on the shell valves (Fig. 3B and E), cracks on whole shell valves in the $1 \mathrm{mM}$ EGCG group (Fig. $3 \mathrm{C}$ and F). Previous studies reported that EGCG had potential to bind and damage to the gram-positive bacterial cell membrane which contain polysaccharides and glycocalyx $[16,17]$. This effect is of particular importance because carbohydrate residues are 

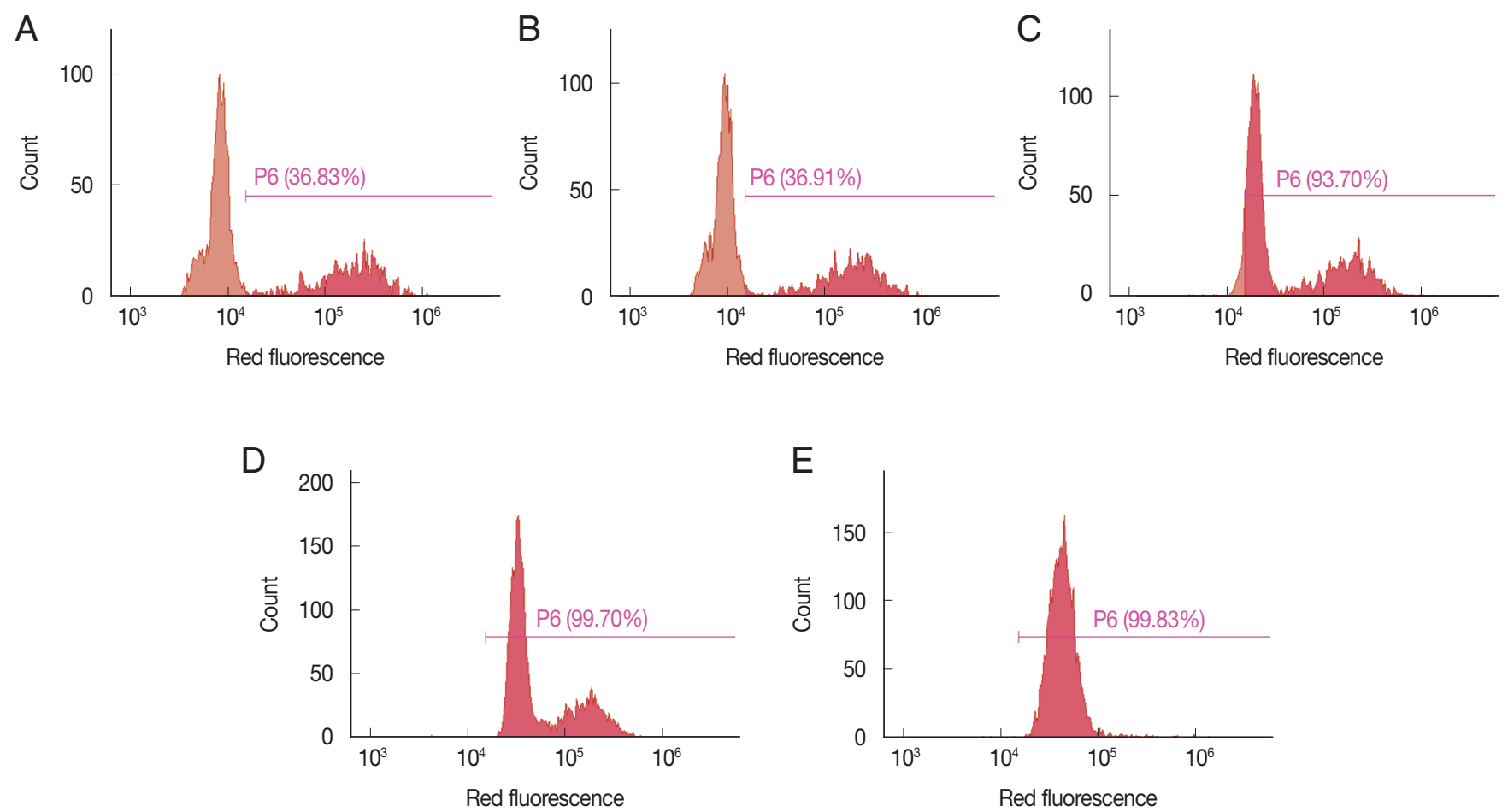

Fig. 2. Assessment of viability of $K$. septempunctata myxospores depends on the concentration of epigallocatechin gallate. Myxospores were treated with (A) phosphate-buffered saline, and (B) 0.01, (C) 0.05, (D) 0.1, and (E) $1 \mathrm{mM}$ epigallocatechin gallate.
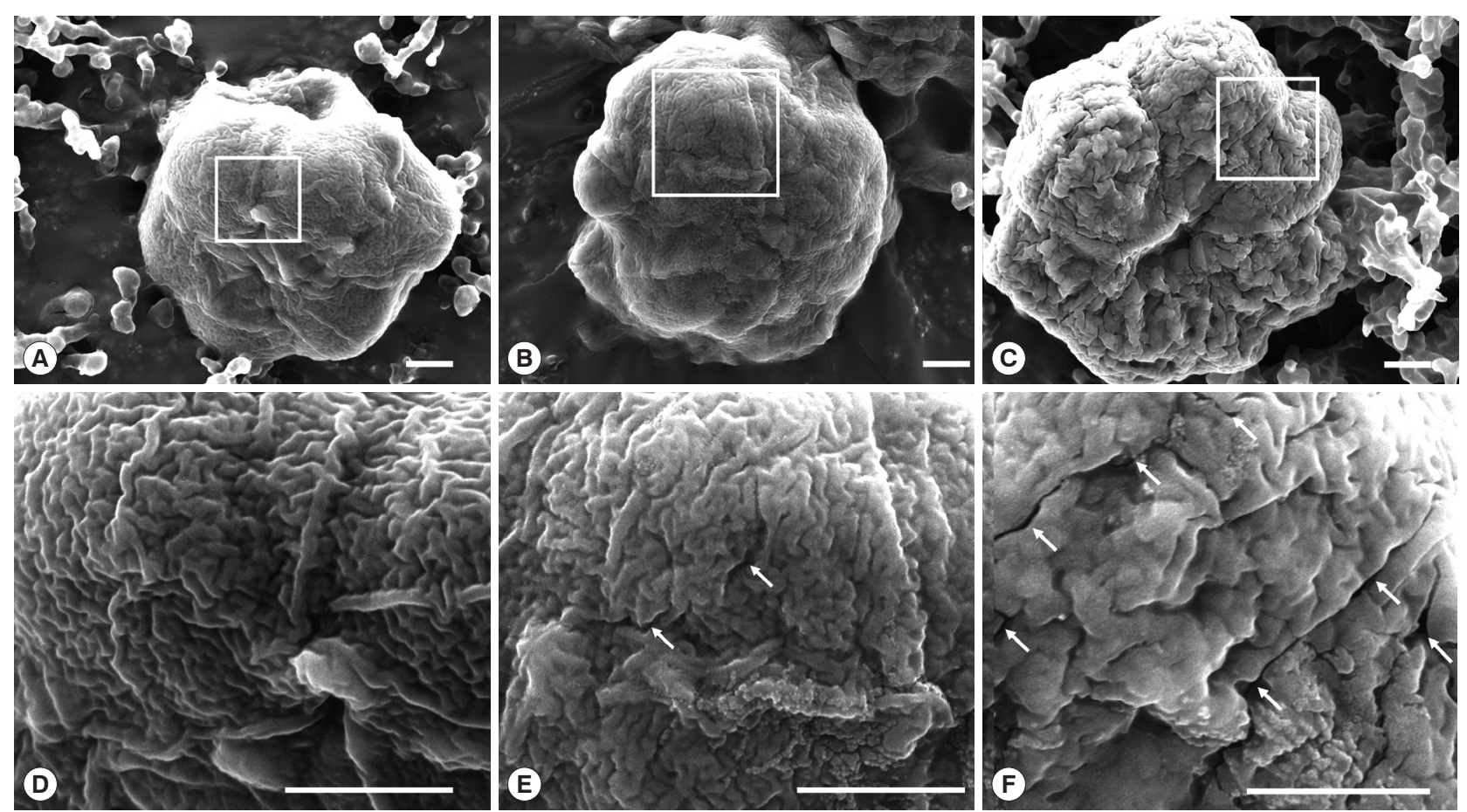

Fig. 3. Scanning electron micrographs of the spores of $K$. septempunctata treated with epigallocatechin gallate. (A) The spores were treated with phosphate buffered saline, (B) 0.1 EGCG, and (C) 1 mM EGCG. (D-F) Magnification of the square regions. Arrow indicates cracks on the shell valve. Scale bar $=1 \mu \mathrm{m}$. 
present in the spore and plasmodial membrane of Kudoa species $[18,19]$. In addition, the carbohydrate residues are participatory in the host-parasite relationships and immune responses in myxosporeans $[19,20]$. It was speculated that EGCG binds to carbohydrate or glycosylated components of the shell valve and damages integrity of the spores. However, further studies are needed to determine the type of cell wall constituents that EGCG binds to and the mechanism of crack formation on the shell valve of $K$. septempunctata.

Application of herbal remedies including EGCG were reported to control disease in the aquaculture, which had low toxicity and minimal environmental impacts [21]. EGCG inhibited grass carp reovirus, white spot syndrome virus, and Vibrio alginolyticus infection in fish, crab, and shrimp [22-24]. However, EGCG to crab caused the hemocyte damages and the administration of EGCG into mouse peritoneum produced severe hepatotoxicity $[23,25]$. We speculate that the sharp increase of EGCG concentration in plasma might cause adverse effects. It is suggested to administer EGCG to fish by adding to aquaculture feed.

In conclusion, EGCG markedly decreased viability of K. septempunctata spores and affected integrity of the shell valves of spores. This finding will contribute to the development of chemotherapeutic agents against the infection of $K$. septempunctata on olive flounders. In addition, flow cytometry could be used to evaluate and quantify the efficacy of chemicals on other myxosporeans. Further studies need to determine an optimal mixing ratio of EGCG to the feed by identifying pharmacokinetics and toxicity of EGCG after oral administering to fish.

\section{ACKNOWLEDGMENT}

This work was done while the author's research year of Jeju National University in 2020.

\section{CONFLICT OF INTEREST}

The authors declare no conflict of interest related to this study.

\section{REFERENCES}

1. Yokoyama H, Grabner D, Shirakashi S. Transmission biology of the Myxozoa. In Carvalho ED, David GS, Silva RJ eds, Health and Environment in Aquaculture. Rejeka, Croatia. InTech. 2012, pp 3-42.

2. Yanagida T. Myxosporean emaciation disease. Fish Pathol 2017; 52: 63-67.

3. Redondo MJ, Palenzuela O, Alvarez-Pellitero P. Studies on transmission and life cycle of Enteromyxum scophthalmi (Myxozoa), an enteric parasite of turbot Scophthalmus maximus. Folia Parasitol 2004; 51: 188-198.

4. Hoffman GL. Myxobolus cerebralis, a worldwide cause of salmonid whirling disease. J Aquat Anim Health 1990; 2: 30-37.

5. Kawai T, Sekizuka T, Yahata Y, Kuroda M, Kumeda Y, Iijima Y, Kamata Y, Sugita-Konishi Y, Ohnishi T. Identification of Kudoa septempunctata as the causative agent of novel food poisoning outbreaks in Japan by consumption of Paralichthys olivaceus in raw fish. Clin Infect Dis 2012; 54: 1046-1052.

6. Ohnishi T, Tomaru A, Yoshinari T, Kamata Y, Sugita-Konishi Y. Detection of myxosporean parasites in unidentified food-borne disease associated with consumption of raw fish. Jap J Food Microbiol 2016; 33: 150-154 (in Japanese).

7. Kawase M, Yoshioka A, Hosoya M, Shichiku M. Suspected foodborne disease related to juvenile Pacific bluefin tuna containing Kudoa hexapunctata and evaluation of patient fecal examination. Jap J Food Microbiol 2015; 32: 48-53 (in Japanese).

8. Ohnishi T, Obara T, Arai S, Yoshinari T, Sugita-Konishi Y. Quantitative analysis of Unicapsula seriolae in Greater amberjack associated with unidentified food-borne disease. J Food Hyg Soc Jpn 2018; 59: 24-29 (in Japanese).

9. Kim WS, Kong KH, Jung SJ, Jung MH, Jeon CH, Kim JH, Oh MJ. A survey of Kudoa septempunctata in olive flounder (Paralichthys olivaceus) hatcheries in the southwestern coast of Korea between 2014 and 2015. J Fish Pathol 2015; 28: 109-112 (in Korean).

10. Yokoyama H, Funaguma N, Kobayashi S. In vitro inactivation of Kudoa septempunctata spores infecting the muscle of olive flounder Paralichthys olivaceus. Foodborne Pathog Dis 2016; 13: 21-27.

11. Ahn MJ, Won SH, Kang BJ, Gong P, Yoo EH, Dharaneedharan S, Jang YH. In vitro effect of two commercial anti-coccidial drugs against myxospores of Kudoa septempunctata genotype ST3 (Myxozoa, Multivalvulida). Parasite. 2017; 24: 11.

12. Ohnishi T, Furuya A, Arai S, Yoshinari T, Goto K, Hara-Kudo Y. Study of tea and coffee on inactivation of Kudoa septempunctata. J Food Hyg Soc Jpn 2019; 60: 22-25 (in Japanese).

13. Kato $\mathrm{S}$, Bowman DD. Using flow cytometry to determine the viability of Cryptosporidium parvum oocysts extracted from spiked environmental samples in chambers. Parasitol Res 2002; 88: 326-331.

14. Soudant P, Chu FL, Lund ED. Assessment of the cell viability of cultured Perkinsus marinus (Perkinsea), a parasitic protozoan of the eastern oyster, Crassostrea virginica, using SYBRgreen-propidium iodide double staining and flow cytometry. J Eukaryot Microbiol 2005; 52: 492-499.

15. Shin SP, Zenke K, Yokoyama H, Yoshinaga T. Factors affecting sporoplasm release in Kudoa septempunctata. Parasitol Res 2015; 114: 795-799.

16. Jeon J, Kim JH, Lee CK, Oh CH, Song HJ. The antimicrobial 
activity of (-)-epigallocatehin-3-gallate and green tea extracts against Pseudomonas aeruginosa and Escherichia coli isolated from skin wounds. Ann Dermatol 2014; 26: 564-569.

17. Steinmann J, Buer J, Pietschmann T, Steinmann E. Anti-infective properties of epigallocatechin-3-gallate (EGCG), a component of green tea. Br J Pharmacol 2013; 168: 1059-1073.

18. Kang J, Park C, Jang Y, Ahn M, Shin T. Lectin histochemistry of Kudoa septempunctata genotype ST3-infected muscle of olive flounder (Paralichthys olivaceus). Parasite 2016; 23: 21.

19. Chase JC, Dawson-Coates JA, Haddow JD, Stewart MH, Haines LR, Whitaker DJ, Ken ML, Olafson RW, Pearson TW. Analysis of Kudoa thyrsites (Myxozoa: Myxosporea) spore antigens using monoclonal antibodies. Dis Aquat Organ 2001; 45: 121-129.

20. Redondo MJ, Alvarez-Pellitero P. Lectin histochemical detection of terminal carbohydrate residues in the enteric myxozoan Enteromyxum leei parasitizing gilthead seabream Sparus aurata (Pisces: Teleostei): a study using light and transmission electron microscopy. Folia Parasitol 2009; 56: 259-267.

21. Zhu F. A review on the application of herbal medicines in the disease control of aquatic animals. Aquaculture 2020; 526: 735422.

22. Wang H. Chen Y, Ru G, Xu Y, Lu L. EGCG: Potential application as a protective agent against grass carp reovirus in aquaculture. J Fish Dis 2018; 41: 1259-1267.

23. Wang Z, Sun BZ, Zhu F. Epigallocatechin-3-gallate inhibit replication of white spot syndrome virus in Scylla paramamosain. Fish Shellfish Immunol 2017; 67: 612-619.

24. Wang Z, Sun BZ, Zhu F. Epigallocatechin-3-gallate protects Kuruma shrimp Marsupeneaus japonicas from white spot syndrome virus and Vibrio alginolyticus. Fish Shellfish Immunol 2018; 78: 1-9.

25. Ramachandran B, Jayavelu S, Murhekar K, Rajkumar T. Repeated dose studies with pure Epigallocatechin-3-gallatedemonstrated dose and route dependant hepatotoxicity with associated dyslipidemia. Toxicol Rep 2016; 3: 336-345. 
